\title{
Profiling The Victims, the Perpetrators And Epidemiological Factors of Road Traffic Incident Under Jurisdiction of NRSMCH Morgue, Kolkata
}

\author{
Dr. Anindya Kumar Goswami, \\ Assistant Professor, Dept of FMT, NRSMCH, \\ Dr. Sayak Sovan Dutta, Assistant Professor, Dept of FMT, NRSMCH
}

\begin{abstract}
:
Context: to identify various epidemiological factors in road traffic incidents in relation to victims, the perpetrators and the incident itself by thorough profiling.

Material and methods: Prospective, cross sectional autopsy based study by sincere analysis of autopsy findings, inquest reports, hospital records and personal interview of the investigating officer and or accompanying persons

Result: Of the total 3614 autopsy examinations during the study period, 588 deaths were related to road traffic incident where males (83.8\%) outnumbered the females as victim and most common age group of fatality was found to be 41-50 years (21.56\%). Most of the incident occurred during summer (38.9\%) and in between 12 noon to $8 \mathrm{pm}$ (43\%), on main road (77.8\%), involving pedestrians (53.9\%)and bus (41.9\%)being the commonest offending vehicle. Alcohol was detected in $27.54 \%$ cases in deceased and $66 \%$ cases in driver of offending vehicle which dashed the pedestrians. $19.74 \%$ cases the drivers of offending vehicles were minor by age.

Conclusions: Road traffic incidents though very much high in number in present days but are preventable too with a little effort from us and also from the law enforcing agencies to combat the issue by close coordination and collaboration among many sectors and disciplines.
\end{abstract}

Keywords: road traffic incident, alcohol, minor.

\section{Introduction}

We want speed, we love speed. We are running behind our dreams constantly. We have enough time to eat, to sleep, to be very much active in social media, but we cannot spend much time on road. We need fastest way of transport to reach our destination. Wasting time on road is simply wastage of our valuable time which could be utilized in other various medium of productivity or even in recreation purposes. And who are we? $\mathrm{We}$ are the people of $21^{\text {st }}$ century. And to run after our success and happiness, automobiles come as an indispensible medium of transport to reach our goals. Along with it comes road traffic incident (we should prefer to call it road traffic incident rather than calling it road traffic accident) - a tragic mode of suffering and death that appears as a curse in this modern jet era causing damage to the body, mind, reputation and property and making such incidents a major medico legal and socioeconomical problem for the society.

All over the world an estimated approx 3 million people die every year from injuries sustained in road traffic incident (WHO report, 1995). Currently, motor vehicle incident cases rank top among all the leading causes of fatal accidents (W.H.O report, 1995). During the year 1998, approximately 80,000 lives were lost and 330,000 people were injured. Of these, $78 \%$ were men in age group of 20-44 years, causing significant impact on productivity of the society (WHO South East Asia Regional Office, 2001). India has only 1\% of the motor vehicles in the world, but carries the burden of $6 \%$ of the global motor vehicle accidents. In every 19 minute a injury related death occurs in India (Sethi AK et al,2001). As per WHO South East Asia Regional Office, 2001, the majority of fatal road traffic incident victims are pedestrians, two wheeler riders and bicyclists. The recent rise of two wheelers which are mainly marketed to attract young riders who want to make their presence clearly felt by their 'riding and driving skills' on the roads, causes more number of road traffic incidents. These riders often violate traffic rules, drive in high speed and indulge in showing off their driving skills frequently leading to fatal outcome to them and also to others. Also not using protective gear either consciously or due to lack of awareness by drivers and their pillion riders while driving simply adding fuel to the burning problem. Moreover India being a developing country consists mainly of lower and middle class people who can afford two wheelers more than four wheelers for simple reasons could be another cause of increase in number of two wheelers on the roads. Considering our city of joy Kolkata being one of the densely populated metropolitan city not only in India but also in the world, along with congested and narrow roads where pedestrian pathways are occupied by 
different categorical professionals especially the hawkers along with simultaneous movement of fast moving vehicles causes unintentional injuries.

Road traffic incidents not only cause morbidity and those cases which terminate in death cause severe economic loss to the society and socioeconomical as well as emotional vacuum in family. The current study aims to create the perfect scene of the incident before the court of law to help proceedings and claims, to aid in administration of justice. Profiling the victims, the perpetrators and various aspects of road traffic injuries as done in this study will be valuable to the law enforcing agencies to evaluate the existing laws on road safety as well as to formulate new laws or to modify existing laws for betterment of us because we suffer for our own fault and also for the fault of others!

Here in this study Post mortem examination is being carried out at NRSMCH Morgue, under the Department of Forensic \& Toxicology, NRS Medical College, Kolkata. During the year 2016, 3614 post mortem examinations were carried out, out of which 588 deaths were due to road traffic incidents. In this study we have made a conscious effort to create the profile in relation to the victims, perpetrators, various aspects of the vehicular 'accident' itself not including the pattern and distribution of injuries with the objective to create awareness among public and law enforcing agencies dealing with such cases to prevent the so called curse of modern jet era- 'the road traffic incident'

\section{Aims And Objectives}

1. To study the various factors and circumstances which lead to the occurrence of road traffic incidents. Specific objectives being:

Factors in relation to the victims. b. Factors in relation to the vehicles involved. c. Factors in relation to the environment

2. To study the type, level of intoxication of alcohol and drugs and its role in the occurrence of the road traffic incidents.

3. To suggest remedial measures pertaining to various factors that favour the occurrence of road traffic incidents.

\section{Materials And Methods}

Study Area: The present study has been carried out in NRSMCH Morgue under the Department of Forensic Medicine and Toxicology, Nil Ratan Sircar Medical College, Kolkata.

Study period: The study period extended from $1^{\text {st }}$ January 2016 to $31^{\text {st }}$ December 2016

Study duration: 12 months.

Study population: During this period total number of 3614 autopsies were carried out in the department, out of these 588 were associated with road traffic incidents. Among which 167 cases were studied depending upon inclusion and exclusion criteria.

Study design: prospective, cross sectional study.

Inclusion criteria: The cases with history of road traffic incidents brought at the NRSMCH Morgue were included in the study.

\section{Exclusion Criteria}

1. Decomposed bodies were excluded from the current study.

2. Though visit to the scene of incident were excluded from the current study but available information regarding the incident were collected from the concerned investigating officers and relatives of the deceased.

3. All autopsies where the nature of incident could not be ascertained (like whether the injuries sustained following road traffic incident or following fall from height) were not included in the study.

Consent: not required here as we collected all the data during medicolegal autopsy which does not require any consent.

Conflict of interest: there is no conflict of interest. The study has been conducted without revealing identification of deceased and there are no economical transactions or any monetary contribution from any person or agencies while conducting the study.

\section{Material used:}

1. Examination of the inquest report.

2. Personal interview of investigating officer and the accompanying police constable. 
3. Interview of accompanying relatives/ friends/ eyewitnesses of the incident and survivor of the same incident, if any.

4. In case of hospitalized victims, hospital records of the treatment.

5. Findings collected from the autopsy examinations performed on the dead body of the victim to ensure the deceased really sustained injuries following road traffic incident and not by other means.

All data that were collected from different sources were then recorded in a specially designed proforma for each case and statistically analyzed using appropriate statistical tools.

History and Causal factors: a comprehensive picture about the background of the victims and the perpetrators were recorded for this study.

\section{Results And Analysis}

A total of 3614 autopsies were performed at NRSMCH Morgue, under the Department of Forensic Medicine and Toxicology, NRS Medical College, Kolkata during the period from $1^{\text {st }}$ January 2016 to $31^{\text {st }}$ December 2016. Of this total no. of road traffic incident cases were 588 .

Table - I

\begin{tabular}{|l|l|l|}
\hline Total No of autopsies & No. Of traffic related cases & Percentage \\
\hline 3614 & 588 & 16.27 \\
\hline
\end{tabular}

Out of 588 cases of road traffic incidents, using inclusion and exclusion criteria 167 cases of road traffic accidents were included in the study.

\section{A. Epidemiological Factors In Relation To Victims:}

1. Age Incidence:

The victims were again divided according to their age into 7 groups of 10 years each up to $>61$ years. The age-wise distribution is shown in the table below.

Table -II Age Distribution of the Cases

\begin{tabular}{|l|l|l|}
\hline Age Group & Frequency & Percentage \\
\hline$<10$ & 7 & 4.19 \\
\hline $11-20$ & 16 & 9.58 \\
\hline $21-30$ & 25 & 14.97 \\
\hline $31-40$ & 33 & 19.76 \\
\hline $41-50$ & 36 & 21.56 \\
\hline $51-60$ & 17 & 10.18 \\
\hline$>60$ & 33 & 19.76 \\
\hline TOTAL & $\mathbf{1 6 7}$ & $\mathbf{1 0 0}$ \\
\hline
\end{tabular}

From the above table it is observed that the highest numbers of victims were in the age group of 41-50 years, and contained a total of 36 cases, comprising $21.56 \%$ of the total number of cases studied. This was followed closely by the group of 31-40 years which contained 33 cases comprising $19.76 \%$ of the total number. The other groups in the order of descending number of cases were 21-30 years with 25 cases(14.97\%), 51-60 years with 17 cases(10.18\%), 11-20 years with 16 cases (9.51\%)and finally $<10$ years with 7 cases $(4.19 \%)$.

\section{Sex incidence:}

Distribution of study subjects according to sex $(\mathrm{n}=167)$

Table - IIISex Distribution of the Cases

\begin{tabular}{|l|l|l|}
\hline \multicolumn{1}{|c|}{ Sex } & No. Of Cases & Percentage \\
\hline Male & 140 & 83.8 \\
\hline Female & 27 & 16.2 \\
\hline TOTAL & 167 & 100 \\
\hline
\end{tabular}

It is observed that from the above table among the 167 cases studied, 140 were male comprising $83.8 \%$ and 27 were female comprising $16.2 \%$ of the total cases.

\section{Religion}

Distribution of study cases according to religion $(\mathrm{n}=167)$ 
Table -IV Religion of the Victim

\begin{tabular}{|l|l|l|}
\hline & NO. OF CASES & PERCENTAGE \\
\hline Hindu & 133 & 79.6 \\
\hline Muslim & 21 & 12.6 \\
\hline Unknown & 13 & 7.8 \\
\hline Total & 167 & 100.00 \\
\hline
\end{tabular}

From the above table it can be deduced that most of the victims were Hindus with 133 cases comprising $79.6 \%$, followed by Muslims with 21 cases comprising $12.6 \%$ and cases with unknown religion were 13 comprising $7.8 \%$.

\section{Marital Status}

Distribution of study cases according to Marital Status $(n=167)$

Table -V Marital status of the Cases

\begin{tabular}{|l|l|l|}
\hline & No. Of Cases & Percentage \\
\hline Married & 102 & 61.1 \\
\hline Unmarried & 52 & 31.1 \\
\hline Unknown & 13 & 7.8 \\
\hline TOTAL & 167 & 100 \\
\hline
\end{tabular}

It is seen from the above table that most of the victims were married with 102 cases $(61.1 \%)$, followed by unmarried with 52 cases(31.1\%) and marital status was unknown of 13 cases(7.8\%)

Distribution Of Victims According To Their Socio-Economical Class: (As Per Modified BG Prasad Scale): Table- VI

\begin{tabular}{|l|l|l|}
\hline Class & Number of cases & Percentage \\
\hline Upper & 7 & 4.1 \\
\hline Upper middle & 05 & 2.9 \\
\hline Middle & 35 & 20.9 \\
\hline Lower middle & 68 & 40.7 \\
\hline Lower class & 52 & 31.1 \\
\hline Total & 167 & 100 \\
\hline
\end{tabular}

It is clearly seen that most of the victims belonged to lower middle class-68 cases (40.7\%), followed by lower class- 52 cases $(31.1 \%)$ where as only $2.9 \%$ belonged toupper middle and $4.1 \%$ belonged to upper class.

\section{Detection Of Alcohol (either by smell during examination or detected subsequently through chemical} analysis):

Table -VII Distribution of study cases according to presence of Alcohol:

\begin{tabular}{|l|l|l|}
\hline & No. Of Cases & Percentage \\
\hline Alcohol present & 46 & 27.54 \\
\hline Absent & 121 & 72.45 \\
\hline TOTAL & 167 & 100 \\
\hline
\end{tabular}

It is seen from the above table that alcohol was found in 46 cases only (27.54\%) and were absent in the remaining 121 cases $(72.45 \%)$. It is interesting to note that all 46 cases smell of alcohol were detected from stomach contents which later came positive through chemical examination report from State FSL. Considering 121 cases where no obvious smell of alcohol detected by the autopsy surgeons from stomach contents, subsequently came negative from State FSL.

\section{Type of road:}

Table -VIII Distribution of Type of Road ( $\mathrm{n}=167)$

\begin{tabular}{|l|l|l|}
\hline & No. Of Cases & Percentage \\
\hline Main Road & 130 & 77.8 \\
\hline Lane & 30 & 18.0 \\
\hline Unknown & 7 & 4.2 \\
\hline TOTAL & 167 & 100 \\
\hline
\end{tabular}

It is seen from the above table that most of the victims in the study had their incidents occurring on the main road with 130 cases(77.8\%), followed by on lane with 30 cases(18.0\%) and the type of road was unknown in 7 cases $(4.2 \%)$. 
Road and vehicle user:

Distribution of cases according to the road user $(n=167)$

Table -IX Distribution of Road User

\begin{tabular}{|l|l|l|}
\hline & No. Of Cases & Percentage \\
\hline Pedestrian & 90 & 53.9 \\
\hline Two Wheeler Occupant & 54 & 32.3 \\
\hline Three Wheeler Occupant & 3 & 1.8 \\
\hline Four Wheeler Occupant & 20 & 12 \\
\hline TOTAL & 167 & 100 \\
\hline
\end{tabular}

It is seen from the above table that most of the victims in the study were pedestrians seen in 90 cases $(53.9 \%)$, followed by two wheeler occupants with 54 cases $(32.3 \%)$, followed by four wheeler occupants in 20 cases(12\%) and three wheeler occupants in 3 cases(1.8\%).

\section{Presence Of Alcohol In Two-Wheeler Occupant: (N=54)}

Table-X Distribution of cases according to detection of alcohol in stomach content in two-wheeler occupant:

\begin{tabular}{|l|l|l|}
\hline Alcohol present or absent & No of cases & Percentage \\
\hline Present & 26 & 48.1 \\
\hline Absent & 28 & 51.8 \\
\hline Total & 54 & 100 \\
\hline
\end{tabular}

From the above table it is seen that among the deceased of two-wheeler occupant, $48.1 \%$ cases found to be positive for presence of alcohol in stomach content where as it was negative in $51.8 \%$ cases.

\section{Presence Of Alcohol In Three-Wheeler Occupant: (N=3) Table-Xi}

\begin{tabular}{|l|l|l|}
\hline Alcohol present or absent & No of cases & Percentage \\
\hline Present & 01 & 33.33 \\
\hline Absent & 02 & 66.66 \\
\hline Total & 03 & 100 \\
\hline
\end{tabular}

From the above table it is seen that among the deceased of three-wheeler occupant, $33.3 \%$ cases found to be positive for presence of alcohol in stomach content where as it was negative in $66.6 \%$ cases.

\section{Presence Of Alcohol In Four-Wheeler Occupant: (N=20) Table- Xii}

\begin{tabular}{|l|l|l|}
\hline Alcohol present or absent & No of cases & Percentage \\
\hline Present & 11 & 55 \\
\hline Absent & 9 & 45 \\
\hline Total & 20 & 100 \\
\hline
\end{tabular}

From the above table it is seen that among the deceased of four-wheeler occupant, 55\% cases found to be positive for presence of alcohol in stomach content where as it was negative in $45 \%$ cases.

Presence Of Alcohol In Pedestrians: (N=90) Table-Xiii

\begin{tabular}{|l|l|l|}
\hline $\begin{array}{l}\text { Alcohol present or } \\
\text { absent }\end{array}$ & No of cases & Percentage \\
\hline Present & 08 & 8.88 \\
\hline Absent & 82 & 91.11 \\
\hline Total & 90 & 100 \\
\hline
\end{tabular}

From the above table it is seen that among the deceased who were pedestrian, $8.88 \%$ cases found to be positive for presence of alcohol in stomach content where as it was negative in $91.1 \%$ cases.

\section{Type Of Vehicle:}

Distribution of victims among the study according to the type of vehicle $(n=167)$

Table -XIV Distribution of cases according to the type of offending vehicle leading to injury

\begin{tabular}{|l|l|l|}
\hline & No. Of Cases & Percentage \\
\hline Two wheeler & 10 & 6 \\
\hline Car/Jeep & 26 & 15.6 \\
\hline Bus & 70 & 41.9 \\
\hline Truck & 28 & 16.8 \\
\hline Tempo & 23 & 13.8 \\
\hline Unknown & 10 & 6 \\
\hline TOTAL & 167 & 100 \\
\hline
\end{tabular}


It is evident from the above table that most common vehicle involved in road traffic accidents was Bus with 70 cases $(41.9 \%$ ), followed by Truck in 28 cases(16.8\%), followed by car/jeep in 26 cases(15.6\%), followed by Tempo in 23 cases(13.8\%), whereas two-wheelers and unknown vehicles both with 10 cases (6\%) each.

\section{Seasonal variation:}

Seasonal variation of occurrence of incidents among the study subjects (n-167)

Table -XVSeasonal variation of occurrence of incidents among the study subjects

\begin{tabular}{|l|l|l|}
\hline & No. Of Cases & Percentage \\
\hline June, July, August & 22 & 13.2 \\
\hline September, October, November & 24 & 14.4 \\
\hline December, January, February & 56 & 33.5 \\
\hline March ,April, May & 65 & 38.9 \\
\hline TOTAL & 167 & 100 \\
\hline
\end{tabular}

June, July, August(RAINY

Season),Sept,Oct,Nov(Autumn),Dec,Jan,Feb(Winter),Mar,Apr,May(Summer)

It is seen from the above table that most of the road traffic incident cases occurred during the summer season with 65 cases $(38.9 \%)$, followed by winter season with 56 cases(33.5\%), followed by autumn season with 24 cases(14.4\%) and ultimately rainy season with 22 cases(13.2\%).

\section{Victim Was Hit From (Pedestrian) :}

Distribution of cases according to the side from which the victim was hit (n-90)

Table -XVI

Distribution of cases according to the side from which the victim was hit

\begin{tabular}{|l|l|l|}
\hline & No. Of Cases & Percentage \\
\hline Front & 4 & 4.4 \\
\hline Back & 37 & 40.66 \\
\hline Rt. Side & 28 & 30.77 \\
\hline Lt. Side & 15 & 16.48 \\
\hline Unknown & 6 & 6.66 \\
\hline TOTAL & 90 & 100 \\
\hline
\end{tabular}

It is seen from the above table that most of the victims (pedestrians only) were hit from the back side in 37 cases $(40.66 \%)$, followed by right side in 28 cases(30.77\%), followed by left side in 15 cases( $16.48 \%)$, followed by front side in 4 cases $(4.4 \%)$. In 6 cases (6.66\%), it was unknown from which side the pedestrian was hit.

Victim was discovered on the spot:

Distribution of study cases according to their status as discovered on the spot (n-167)

Table - XVII Distribution of study cases according to their status as discovered on the spot

\begin{tabular}{|l|l|l|}
\hline & No. Of Cases & Percentage \\
\hline Conscious & 41 & 24.6 \\
\hline Unconscious & 83 & 49.7 \\
\hline Dead & 43 & 25.7 \\
\hline TOTAL & 167 & 100 \\
\hline
\end{tabular}

It is seen from the above table that most of the victims were found unconscious at the place of incidence of accident in 83 cases $(49.7 \%)$, followed by found dead in 43 cases $(25.7 \%)$ and found conscious in 41 cases $(24.6 \%)$.

Victim Hospitalised Or Not:

Distribution of cases according to the hospitalization of the victims (n-167)

Table -XVIII Distribution of cases according to the hospitalization of the victims

\begin{tabular}{|l|l|l|}
\hline & No. Of Cases & Percentage \\
\hline Hospitalized & 124 & 74.25 \\
\hline Not Hospitalized (SPOT DEAD) & 43 & 25.74 \\
\hline Total & 167 & 100 \\
\hline
\end{tabular}


It is seen from the above table that a majority of the victims were hospitalized after the incident in 124 cases $(74.25 \%)$ and remaining victims were not hospitalized in 43 cases $(25.74 \%)$.

Time Interval Between Incidence And Time Of Admission In Hospital: (Among Hospitalized Patients $\mathbf{N}=124)$

Table -XIX Distribution of study cases according to time interval between accident and time of admission

\begin{tabular}{|l|l|l|}
\hline & No. Of Cases & Percentage \\
\hline$<30$ Minutes & 52 & 41.9 \\
\hline 30 Minutes $-1 \mathrm{Hrs}$ & 6 & 4.8 \\
\hline $1 \mathrm{Hrs}-2 \mathrm{Hrs}$ & 26 & 20.9 \\
\hline $2 \mathrm{Hrs}-6 \mathrm{Hrs}$ & 24 & 19.3 \\
\hline$>6 \mathrm{Hrs}$ & 16 & 12.9 \\
\hline TOTAL & 124 & 100 \\
\hline
\end{tabular}

It is seen from the above table that 52 cases $(41.9 \%)$ were hospitalized in less than 30 minutes, 24 cases $(19.3 \%)$ were hospitalized between 2-6 hours, 16 cases $(12.9 \%)$ were hospitalized in greater than 6 hrs after incident, 26 cases $(20.9 \%)$ were hospitalized between 1-2 hrs after incident and 6 cases(4.8\%) were hospitalized in between 30 minutes-1 hour after the incident.

\section{Time Of Incident:}

Table -XX Distribution of study cases according to the time of incidence

\begin{tabular}{|l|l|l|}
\hline Time of Incidence & Frequency & Percentage \\
\hline 6 a.m. -12 noon & 28 & 16.77 \\
\hline 12 noon -8 p.m. & 72 & 43.11 \\
\hline 8 p.m. -6 a.m. & 67 & 40.12 \\
\hline TOTAL & 167 & 100.00 \\
\hline
\end{tabular}

It is seen from the above table that most of the road traffic incidents occurred between 12 noon to 8 p.m. as seen in 72 cases $(43.11 \%)$, followed by between the time interval 8p.m. to 6a.m. with 67 cases $(40.12 \%)$ and least between 6 a.m. to 12 noon with 28 cases( $16.77 \%)$.

\section{Place Of Death Of The Victim:}

Table -XXI Distribution of study cases according to their place of death

\begin{tabular}{|l|l|l|}
\hline & No. Of Cases & Percentage \\
\hline Spot & 43 & 25.7 \\
\hline Hospital & 124 & 74.25 \\
\hline TOTAL & 167 & 100 \\
\hline
\end{tabular}

It is seen from the above table that most of the victims as seen in 124 cases(74.25\%) died in the hospital during treatment, followed by 43 cases $(25.7 \%)$ died on the spot.

Duration Of Survival: (among hospitalized patients, $n=124$ )

Table -XXII Distribution of study cases according to their duration of survival $(n=124)$

\begin{tabular}{|l|l|l|}
\hline & No. Of Cases & Percentage \\
\hline$<1 \mathrm{Hrs}$ & 65 & 52.41 \\
\hline 1 Hrs - 3 Hrs & 12 & 9.67 \\
\hline 3 Hrs -6 Hrs & 16 & 12.90 \\
\hline 6 Hrs - 12 Hrs & 4 & 3.22 \\
\hline 12 Hrs - 1 Day & 7 & 5.64 \\
\hline 1 Day - 3 Days & 9 & 7.25 \\
\hline 3 Days - 7 Days & 6 & 4.83 \\
\hline$>7$ days & 5 & 4.03 \\
\hline TOTAL & 124 & 100 \\
\hline
\end{tabular}

It is seen from the above table that most of the victims survived for less than 1 hour after incident as seen in 65 cases $(52.41 \%)$, followed by16 (12.9\%) cases who survived between 3-6 hours of hospital admission and only $5(4.03 \%)$ persons died after 7 days of hospital admission. 
Profiling The Perpetrators: (All The Cases Information Gathered From Investigating Officers) Age Of The Perpetrators:

Those Who Dashed The Pedestrian: (N=90) Table: Xxiii
\begin{tabular}{|l|l|l|}
\hline Age Group & NO OF CASES & PERCENTAGE \\
\hline Less Than 18 Years & 04 & 4.4 \\
\hline 18to 60 Years & 72 & 80 \\
\hline Above 60 Years & 10 & 11.1 \\
\hline Unknown & 04 & 4.4 \\
\hline Total & 90 & 100 \\
\hline
\end{tabular}

It is evident from the study that pedestrian were dashed by vehicles which by driven by the driver whose age was less than 18 years in $4.4 \%$ cases, above 60 years in $11 \%$ cases but majority of them were between $18-60$ years in $80 \%$ cases.

Distribution Of Drivers Of Offending Vehicle Who Were Driving Under Influence Of Alcohol And Dashed The Pedestrians: (Excluding 04 Unknown Cases As Mentioned Above) $(\mathrm{N}=86)$

Table-Xiv

\begin{tabular}{|l|l|l|}
\hline Drunken Driving & No Of Cases & Percentage \\
\hline Yes & 57 & 66.27 \\
\hline No & 29 & 33.72 \\
\hline Total & 86 & 100 \\
\hline
\end{tabular}

It is alarming to note that most of the drivers who dashed the pedestrians where driving under influence of alcohol as seen here in $66.2 \%$ cases.

Distribution Of Drivers Of Two-Wheeler Vehicle Who Were Driving Under Influence Of Alcohol: (N=10) Table: $\mathrm{Xxv}$

\begin{tabular}{|l|l|l|}
\hline Drunken Driving & No Of Cases & Percentage \\
\hline Yes & 05 & 50 \\
\hline No & 03 & 30 \\
\hline Unknown & 02 & 20 \\
\hline Total & 10 & 100 \\
\hline
\end{tabular}

It is evident in this study that the Drivers of two wheeler offending vehicle were driving under influence of alcohol in $50 \%$ cases.

Distribution Of Drivers Of Truck Who Were Driving Under Influence Of Alcohol: (N=28) Table: Xxvi

\begin{tabular}{|l|l|l|}
\hline Drunken Driving & No Of Cases & Percentage \\
\hline Yes & 15 & 53.57 \\
\hline No & 11 & 39.28 \\
\hline Unknown & 02 & 7.14 \\
\hline Total & 28 & 100 \\
\hline
\end{tabular}

It is evident in this study that the drivers of offending truck were driving under influence of alcohol in $53.57 \%$ cases.

Distribution Of Drivers Of Bus Who Were Driving Under Influence Of Alcohol: (N=70) Table: Xxvii

\begin{tabular}{|l|l|l|}
\hline Drunken Driving & No Of Cases & Percentage \\
\hline Yes & 05 & 7.1 \\
\hline No & 65 & 92.85 \\
\hline Unknown & 00 & 00 \\
\hline Total & 70 & 100 \\
\hline
\end{tabular}

It is evident in this study that the drivers of offending bus were driving under influence of alcohol in $7.1 \%$ cases only.

Distribution Of Drivers Of Tempo Who Were Driving Under Influence Of Alcohol: (N=23) Table: Xxviii

\begin{tabular}{|l|l|l|}
\hline Drunken Driving & No Of Cases & Percentage \\
\hline Yes & 10 & 43.47 \\
\hline No & 12 & 52.17 \\
\hline Unknown & 01 & 4.34 \\
\hline Total & 23 & 100 \\
\hline
\end{tabular}

It is evident in this study that the drivers of offending Tempo were driving under influence of alcohol in $43.4 \%$ cases. 
Profiling The Victims, The Perpetrators And Epidemiological Factors Of Road Traffic....

Distribution Of Drivers Of Car/Jeep Who Were Driving Under Influence Of Alcohol: (N=26) Table: Xxix

\begin{tabular}{|l|l|l|}
\hline Drunken Driving & No Of Cases & Percentage \\
\hline Yes & 12 & 46.15 \\
\hline No & 13 & 50 \\
\hline Unknown & 01 & 3.84 \\
\hline Total & 26 & 100 \\
\hline
\end{tabular}

It is evident in this study that the drivers of offending Car were driving under influence of alcohol in $46.15 \%$ cases.

Distribution Of Drivers Of Offending Vehicle According To Their Age Group Below 18 Years:

Table- XXX (Excluding Unknown Cases, So 167-10=157)

\begin{tabular}{|l|l|l|}
\hline age less than 18 years & no of cases & respective percentage \\
\hline driver of two-wheeler & 05 out of 10 & 50 \\
\hline driver of bus & 00 out of 70 & 00 \\
\hline driver of truck & 06out of 28 & 21.42 \\
\hline driver of tempo & 07 out of 23 & 30.43 \\
\hline driver of car & 13 out of 26 & 50 \\
\hline total & 31 out of 157 & 19.74 \\
\hline
\end{tabular}

It is seen that $19.74 \%$ cases the driver of the offending vehicle was minor by age.

\section{Discussion}

- Study population: table-I

- Out of 3614 cases of autopsy done in NRSMCH Morgue, 588 cases were related to road traffic injuries which comprise $16.27 \%$ of all cases done in the year of 2016 that is from $1^{\text {st }}$ January 2016 to $31^{\text {st }}$ December 2016 among which 167 cases were selected for this study depending upon inclusion and exclusion criteria.

- Devi T.M. et al (1998) reviewed the fatal two-wheeler road traffic accident cases that were autopsied in the Dept. of Forensic Medicine, Regional Institute of Medical Science, Imphal during the year 1991-1996. Out of the total number of 2163 autopsies conducted in the department, the cause of death due to vehicular accidents was $493(22.76 \%)$.

- In their study carried out in the Department of Forensic Medicine, RIMS, Imphal, Momonchand et al (1988), found that, out of the total 310 autopsies carried out during 1985-87, 135 cases (43.5\%) were death due to vehicular accidents. The figures in our present study show that, involvement of such accidents is almost halved in this part of the country.

- $\quad$ Age of the deceased: TABLE-II

- Most of the deceased belonged to the age group of $41-50$ years which is $21.56 \%$ of the total number of cases studied. This was followed closely by the group of 31-40 years which contained 33 cases comprising $19.76 \%$ of the total number, whereas the victims less than 10 years was only $4.19 \%$ of study population.

- Pillay V.V. (1992) in a study carried out in Coimbatore city in South India found the commonest age group to be 21-30 years.

- Kumar A. et al (1999), in their study carried out in Agra, found that most of the victims in their study were young adults; age group involved being 21-30 years (29.45\%) and 31-40 years $(27.89 \%)$.

- Chandra J. (1979) in their study at Delhi found the most common group involved in road traffic accidents to be 21-40 years of age.

- Sex of the deceased: TABLE-III

- Most of the victims were male comprises $83.8 \%$ of the study cases.

- Salgado M.S.L. et al (1988) in a study carried out in the office of the Judicial Medical Officer, Colombo for a period of two years ending December 1985 found 443(84.5\%) cases to be male and 81(15.5\%) female out of total 524 cases they studied.

- Adeyemo A.O. et al (1984) in Nigeria found 127(85.81\%) male and 21(14.19\%) female victims among 148 cases he studied.

- Santhiyasekaran B.W.C (1991) found $82.5 \%$ of the victims to be male and $17.5 \%$ to be female.

- Basu R. et al (1992) found 174(87\%) of the victims were male as against 26(13\%) female out of total 200 cases they studied.

- $\quad$ Religion of the deceased: TABLE-IV 
- The present study shows that, the numbers of victims from Hindu community are far more than from any other communities. The number of such victims was 133(79.6\%) compared to $21(12.6 \%)$ among Muslims and the religion of $13(7.8 \%)$ was not known. However, similar data could not be made available for comparison with the present study. Preponderance of Hindus can be explained by the demographical patterns of this region.

- Marital status of the deceased: TABLE-V

- Majority of the cases studied in this study were married making up $102(61.1 \%)$ cases and 52(31.1\%) were unmarried and in $13(7.8 \%)$ cases the marital status was unknown.

- Socio-economical class of the deceased: TABLE-VI

- Most of the deceased belonged to lower middle class-68 cases (40.7\%), followed by lower class- 52 cases (31.1\%) where as only $2.9 \%$ belonged to upper middle and $4.1 \%$ belonged to upper class

- A study by P.V.Srinivasa Kumar*, K.Srinivasan, showed that majority of accidents (63.9\%) occurred in upper middle class group of SES scale, followed by (23\%) in lower middle class of socio economic status.

- In another study done by Yogesh Balaso Patil and Mohan Khamgaonkar revealed SE Class of the deceased belonged to Upper 1\%, Upper middle 11 3.67\%, Lower middle 28 9.33\%, Upper lower $43.33 \%$ and Lower $42.67 \%$.

- In 'An epidemiological study of road traffic accident cases attending a tertiary care hospital', by Tirupati P Shakeer Kahn, R Altaf Hussain Socio economic status of Upper class 6.3\% Upper Middle class $10.4 \%$, Lower Middle class $20.0 \%$ Upper Lower $44.1 \%$ and in Lower class $19.2 \%$

- Type of road: TABLE- VIII

- The highest number of victims in the study met their accidents in main road $77.8 \%$, followed by lane $18 \%$ and unknown in $4.2 \%$.

- Norman (1952) cited that a higher proportion of accidents in the rural area were fatal.

- Hoffman D. (1976) asserted that the number of dead person is much higher in rural areas.

- Mootoo L. (1988) reported on the basis of fhis study conducted in the country of Guyana that $78 \%$ of his victims died in accidents that took place in the countryside.

- According to a report of the Central Road Research Institute (1997), 23 major cities of India accounted for $15 \%$ of the total road fatalities. This shows that the proportion of fatal accidents in urban areas is more in our part of the country in comparison to all India figures.

- Road User: Table-IX

- In this study it was found that most of the victims in the study were pedestrians seen in 90 cases(53.9\%), followed by two wheeler occupants with 54 cases(32.3\%), followed by four wheeler occupants in 20 cases $(12 \%)$ and three wheeler occupants in 3 cases(1.8\%).

- Perry J.F. et al (1964) studied the victims of road traffic accidents and found out of 127 fatal injuries, 57 pedestrians, 64 auto-occupants, 6 motorcyclists and 6 bicyclists. The preponderance of occupants seen in the study is not similar to the present study.

- Aggarwal G. et al (1988) found that pedestrians (66.2\%) were the commonest victims in their study followed by scooterists $(15.5 \%)$.

- Type of Vehicle Involved: Table- XIV

- In this study it was found that most common vehicle involved in road traffic accidents was Bus with 70 cases(41.9\%), followed by Truck in 28 cases(16.8\%), followed by car/jeep in 26 cases(15.6\%), followed by Tempo in 23 cases(13.8\%), whereas two-wheelers and unknown vehicles both with 10 cases (6\%).

- David et al (1975) observed in their studies that knocking down of pedestrians by four-wheeled and sixwheeled vehicles were the most common cause.

- Chandra J. et al (1979) in their study found that 4- wheeler and heavy vehicles viz. trucks and buses to be the main offending vehicles in road traffic accidents.

- Seasonal variation: TABLE- XV

- It is seen from the above table that most of the road traffic incident cases occurred during the summer season with 65 cases $(38.9 \%)$, followed by winter season with 56 cases(33.5\%), followed by autumn season with 24 cases(14.4\%) and ultimately rainy season with 22 cases(13.2\%). 
- Mazurek A. J. (1994) made an epidemiological study of pediatric injury following road traffic accidents and found that most injuries occurred in summer.

Kumar A. et al (1999) in their study found that the number of cases and mortality were maximum in the rainy season

Starks H.J.H (1952) observed a distinct summer peak of the incidence of motorcycle accidents in contrast to a winter peak for other vehicular accidents.

- Detection of alcohol in stomach content in deceased: Table- VII, X, XI, XII, XIII

- The current study shows that alcohol was found in 46 cases, comprising $27.54 \%$ of study population. Alcohol was found in $48 \%$ cases among two-wheeler occupant, $33.3 \%$ cases in three-wheeler occupant, $55 \%$ cases in four wheeler occupant and $8.8 \%$ cases in cases of pedestrians succumbed to death.

- Age of the driver of offending vehicle who dashed pedestrians: Table- XXIII

- While profiling the perpetrators information were gathered from the Investigating police officer during autopsy as well as later on for necessity of this particular study

- It is evident from the study that pedestrian were dashed by vehicles which by driven by the driver whose age was less than 18 years in $4.4 \%$ cases, above 60 years in $11 \%$ cases but majority of them were between $18-60$ years in $80 \%$ cases.

- Considering the overall the age of the drivers of offending vehicle who were minor by age found to be $19.74 \%$ of cases as evident in table no XXX.

- Observations noted in table no XIV, XXV, XXVI, XXVII, XXVIII, and XXIX:

It was seen that the drivers of offending vehicle who dashed pedestrians where driving under influence of alcohol in $66.27 \%$ cases, those who were driving two-wheeler (motor cycle) in 50\% cases, were driving a truck in $53.57 \%$ cases, a bus in $7.1 \%$ cases, a tempo in $43.47 \%$ cases and a car in $46.15 \%$ cases. It is very much clear from the study that most of the pedestrians died rather became victims of drunken driving. The percentage were also very much high in cases of two-wheeler and in cases of truck drivers. In one study titled 'Relationship between Road Traffic Accidents and Drinking Habits in All 47 Prefectures of Japan' by Nobuyuki Miyatake, Naoko Tanaka et all revealed Drinking habits was significantly and negatively correlated with injured subjects due to road traffic accidents. However, road traffic accidents due to drinking was positively correlated with injured subjects due to road traffic accidents $(r=0.492, p=0.0004)$.

Another study in this field done by T.Sivakumar and Dr.R.Krishnaraj, they found that proportion of injuries 'linked' to alcohol use was $58.9 \%$ of all injuries with $24 \%$ due to own drinking and $35 \%$ due to others drinking. It was found that on the types of injuries amongst alcohol users, $46 \%$ was due to road accidents. A study from Kerala State conducted by the Alcohol \& Drug Information centre revealed around $40 \%$ of the road accidents have occurred because the driver was under the Influence of alcohol. In the case of accidents on National Highways, more than $72 \%$ were related drinks driving.

In a survey done at Delhi by the Directorate of Prohibition, it was found that $45 \%$ of vehicles are driven by drivers who had consumed alcoholic drinks. Car owners who attend dinners / parties tend to get drunk, indulge in rash driving and are unable to control the vehicle and meet with accidents. About $60 \%$ and $65 \%$ of accidents are being caused by drunken drivers of cars and two wheelers during the night and early hours of the morning. Drivers aged 16 to 21 years have highest rate of alcohol involved fatal accidents in United States even though lower average Blood Alcohol Concentration (BAC) were found than in older drivers. But in India (where significant research in this field is lacking) this age group can be identified between 20 to 25 years.

\section{Conclusion \& recommendations:}

This study aims to contribute to some knowledge on road safety by thorough profiling of the victims, the perpetrators as well as various aspects of road traffic injury itself with an expectation to facilitate increased interdisciplinary cooperation and sincere commitment from ourselves to prevent road traffic incidents.

One thing to be kept in mind that road traffic incidents though very much high in number in present days but are preventable too with a little effort from us and also from the law enforcing agencies to combat the issue by close coordination and collaboration among many sectors and disciplines.

\footnotetext{
The major problems revealed in our study are as follows:

1. Drunken driving both in cases of perpetrators and in deceased

2. Age of the driver in many cases were below legal age of driving

3. Inadequate ambulatory services to transport the victim from spot to hospital

4. Inadequate rather deficiency in number of trauma care centres.
} 
From the observations made in our study we like to recommend the followings:

$>$ Making provision of adequate foot-paths for pedestrians and strict prevention of encroaching of foot-paths by hawkers.

$>$ Setting and enforcing appropriate speed limits on specific roads

$>$ Setting and enforcing laws regarding occupants of the vehicles to wear safety belts, similarly wearing helmets for the rider and pillion rider of two-wheelers.

$>$ Strict monitoring on drivers to check blood alcohol concentration and strict implication of existing laws on 'drunken driving'

Dhile issuing driving licence proper care should be taken to hand over the licence who are really worthy of it.

$>$ Law enforcing agencies should look after that only the person above the legal age of driving uses the car to drive.

> Driver education courses should be made more approachable and taught sincerely along with constant motivation by using different social media platforms

$>$ Urgent improvement in trauma care centres by their number and as well as infrastructures and adequate and equipped ambulatory services.

All though there are so many studies on road traffic injuries, still we hope this study will give a little contribution in the same field by better understanding the epidemiological factors involving vehicular fatality by thorough profiling of various factors and circumstances which lead to the occurrence of road traffic incidents. Lastly we strongly believe it is the problem created by us leading to our own sufferings as well as suffering of others. Blaming only law enforcing agencies will not solve the problem until we are motivated for our personal security on roads. A little cooperation and sincere motivation from our side can easily solve the so called curse of this modern jet era.

\section{References}

[1]. Aguwa C.N, Anosike E0, and Akubue P I, (1982) Road accidents in Nigeria: Level of alcohol in the blood of automobile drivers. Central African journal of Medicine.28: 171-174.

[2]. Association for the Advancement of Automotive Medicine, Illinois, USA: The Abbreviated Injury Scale (AIS), 1990 Revision.

[3]. Batra VS, Bedi RB. Effect of Drunken driving on traffic safety.

[4]. Basu R., Nandy A., Mukhopadhyay B.B. and Majumder B.C.: Some host factors and seasonal variation in the fatal road traffic accident occurring in old Coroner's Calcutta, --a scientific paper in the XIV Annual Conference of the Indian Association of Forensic Medicine, 1992

[5]. Bradbury B.R., Robertson C. Prospective audit of the pattern, severity and circumstances of injury sustained by vehicle occupants as a result of road traffic accidents, Archive of Emergency Medicine, March 1993, Vol.10, No.1 : 15-23

[6]. Bureau of Police research and Development, Ministry of home Affairs, Govt. of India, research report, 1970, Qtr. 1, 2:6.

[7]. CAREC Surveillance Reports. (1987) Blood alcohol level in accident victims- Surinam February 1987. CAREC Surveillance Reports. 13,1-4.

[8]. Central Road Research Institute, New Delhi, Annual Report, 1997.

[9]. Crore M.A., Epidemiology of motor vehicular accident, JAMA, 1992; 981:210

[10]. David S. and Sundaram C.L.: Traffic accident analysis of cases during 1961 1970, Journal of Indian Academy of Forensic Sciences, Vol. 14, No.2,: 28-34 Department of Transport, United States: report dated June 1999, November 2001 (through Internet)

[11]. Everest, J. Tunbridge, R. and Widdop, B. (1989). The incidence of drugs in road accident fatalities. Research Report RR202. Crowthorne: TRL Limited

[12]. Fosseus CG. (1983) Motorcycle accidents and alcohol. A survey of fatalities in Cape Peninsula, South Africa medical journal 64 (5), 159-160.

[13]. Govt. of India, Central Statistical Organization, Ministry of Statistics \&

[14]. Programme Implementation, New Delhi, Govt. of India, 2000.

[15]. O.T.: Age, sex and blood alcohol concentration of killed and injured pedestrians, Accident Annual review, 1995, 27:417-22

[16]. Hoffman, E. Annul of Royal College of Surgery, England, 1976, 58:233.

[17]. Jha M, Srinivasa, Roy G, Jagdish S.: Epidemiology Study of Road Traffic Accident Cases: A study From South India. Indian Journal of Community

[18]. Medicine, Volume XXIX, Number 1 January-March, 2004.

[19]. Jha N. Road Traffic Accident Cases at BPKHS, Dharan, Nepal: one year in retrospect. J Nepal Med Assoc 1997; $35: 241-4$.

[20]. Lynam 0, Broughton J, Minton R and Tunbridge R.J: An Analysis of police

[21]. reports of fatal accidents involving motorcycles, Department of the Environment, Transport and the Regions, 2001.

[22]. McFarland R.A. et al: The epidemiology of motor vehicle accidents, JAMA,

[23]. 1982, 801:289

[24]. Mohan D, Bawa PS, An analysis of road traffic fatalities in Delhi, India. Accid Anal Pre ${ }^{\mathrm{y}}$. 1985;17:33-45.

[25]. Norman L.G.: Road traffic accident, World Health Organisation, 1952, 3:47

[26]. Peden MM. et al (2001): The sentinel surveillance of substance abuse and trauma, 1999-2000; Final Report. Medical Research Council, Tygerberg.

[27]. Pillay V.V.: Indian Academy of Forensic Medicine. Scientific article of XIV Annual Conference 1992, Jan $4^{\text {th }}$ - 11th

[28]. Salgado M.S.L. \& Colornbage S.M. Analysis of fatalities in road accidents. Forensic Science International 1988; 36: $91-96$

[29]. R.A. and Pons P.T.; Epidemiology of trauma deaths - a reassessment; Journal of trauma. February 1995, Vol.38, No.2, $185-192$. 
[30]. Shivkumar P. A typical fatal road accident - A case report, Indian Journal of Forensic Sciences, Oct 1992. 6 173-4,

[31]. Verma P.K, Tewari KN.: Epidemiology of Road Traffic Injuries in Delhi: Result of a Survey, Regional Health Forum WHO South-East Asia Region. Vol 8 No. 1,2004.

[32]. WHO Report, 'Road safety is no accident' published on World Health Day, 7th April 2004, Geneva, WHO: 2001 